\title{
KARTU INDEKS DAN SOAL-SOAL TERSTRUKTUR BERBASIS (INFORMATION AND COMMUNICATION TECHNOLOGY) ICT TERHADAP HASIL BELAJAR
}

\author{
Dian Safitri ${ }^{1}$, Suhaedir Bachtiar ${ }^{2}$ \\ ${ }^{1}$ Jurusan Pendidikan Biologi, Fakultas Tarbiyah dan Keguruan, UIN Makassar \\ ${ }^{2}$ SMPN 2 Batang, Desa Maccini Baji Kecamatan Batang Kabupaten Jeneponto \\ ${ }^{1}$ Email: Dian.Safitri_H@yahoo.com \\ ${ }^{2}$ Email: subha.3g@gmail.com
}

\begin{abstract}
Abstrak: Penelitian ini bertujuan untuk mengetahui pengaruh penggunaan kartu indeks dan soal terstruktur berbasis ICT terhadap hasil belajar. Penelitian eksperimen semu dengan desain Randomized Control-Group Only Design. Populasi penelitian adalah seluruh siswa kelas XI SMA Negeri 17 Makassar. Besarnya sampel ditetapkan sebanyak 56 responden. Penentuan sampel yaitu secara acak kelas. Data dianalisis menggunakan statistik deskriptif dan inferensial. Hasil penelitian menunjukkan bahwa ada pengaruh penggunaan kartu indeks dan soal-soal terstruktur berbasis ICT terhadap hasil belajar.
\end{abstract}

Kata Kunci : Ict, Kartu Indeks, Hasil Belajar.

\section{CARD INDEX AND QUESTIONS STRUCTURED (BASED ON INFORMATION AND COMMUNICATION TECHNOLOGY) OF THE RESULTS OF THE STUDY}

\begin{abstract}
: this study aims to in order to understand the the influence of the use of index card structured but only fancies and based ict of the results of the learning. The course of this experiment research deceitful illusions with the design randomized control-group only including on the instrument types. Percent of the population research is that an entire kind student of class XI public senior high schools 17 Makassar. The size of the sample as many as 56 it has been determined that a significant proportion of respondents. The determination of of the sample at random a class of. The data have been analyzed uses statistics descriptive and inferential. The research results show that there an effect the use of the other hand the cards the index and questions structured based ICT of the results of the learning.
\end{abstract}

Keywords: Ict, Card Index, Study Results 
Materi pembelajaran akan lebih mudah dipahami oleh siswa, jika guru menggunakan alat bantu belajar-mengajar yang dikenal dengan istilah media pembelajaran. Media ini dapat berupa benda sesungguhnya, imitasi atau tiruan yang bisa berupa gambar, grafik, tabulasi yang dituangkan dalam media baik visual, audio maupu elektronik. Penggunaan media harus sesuai dengan tujuan, materi dan metode pembelajaran. Pada awalnya media merupakan alat bantu pembelajaran berupa visual, dengan harapan dapat memberikan pengalaman kongkret, meningkatkan motivasi belajar dan mempertinggi daya serap siswa. Seiring dengan perkembangan ilmu pengetahuan dan teknologi, penggunaan alat bantu juga turut berkembang dari visual menjadi audio, dan media tiga dimensi (model). Akhir-akhir ini kemajuan ilmu pengetahuan dan teknologi memberikan peluang penggunaan komputer dalam proses pembelajaran. Hal ini berangkat dari kesuksesan teknik presentasi yang digunakan di berbagai perusahaan dengan menggunakan multimedia

Media merupakan perantara atau pengantar terjadinya pesan dari pengirim ke penerima pesan (Sadiman, 2001). Secara umum pengertian media adalah alat, metode dan tehnik yang digunakan dalam rangka lebih mengefektifkan komunikasi dan interaksi antara guru dan siswa dalam proses pembelajaran di sekolah (Hamalik, 1994). Media dapat didefenisikan sebagai segala bentuk dan saluran yang digunakan orang untuk menyalurkan pesan atau informasi (Sadiman, 2001). Kedua pendapat tersebut juga relevan dengan pendapat bahwa media adalah perantara atau pengantar (Djamarah dan Zain, 2002). Seiring dengan perkembangan ilmu pengetahuan dan teknologi, penggunaan alat bantu juga turut berkembang dari visual menjadi audio, dan media tiga dimensi (model).

Fungsi media yang berbasis teknologi adalah membuat kongkrit konsep yang abstrak, membawa objek yang sukar di dapat dalam lingkungan belajar, menampilkan objek yang terlalu besar, menampilkan objek yang tidak dapat diamati, mengamati gerakan yang terlalu cepat, memungkinkan siswa berinteraksi langsung dengan lingkungan, memungkinkan keseragaman pengamatan dan persepsi pengalaman belajar siswa, membangkitkan motivasi belajar, memberi kesan individual untuk seluruh anggota kelompok, menyajikan pesan atau informasi belajar secara serempak, mengatasi batasan waktu dan ruang, dan mengontrol arah maupun kecepatan belajar siswa (Djamarah, 2002).

Belajar adalah berusaha atau berlatih supaya dapat memperoleh kepandaian (Poerwadarminta, 1996). Belajar juga dapat didefinisikan sebagai aktivitas yang dilakukan individu secaraa sadar untuk mendapatkan sejumlah kesan dari apa yang telah dipelajari dan sebagai hasil interaksinya dengan lingkungan sekitarnya (Slameto, 1995). Belajar dapat didefinisikan sebagai upaya perubahan tingkah laku dengan serangkaian kegiatan, seperti membaca, mendengar, mengamati, meniru dan sebagainya. Atau belajar sebagai kegiatan psikofisik untuk menuju ke perkembangan pribadi seutuhnya. Oleh 
karena dalam belajar perlu ada proses internalisasi, sehingga akan menyangkut mitra kognitif, efektif dan psikomotorik (Sadiman, 2001).

Sekolah Menengah Atas Negeri 17 Makassar, selama ini guru mengajar dengan menggunkaan metode ceramah saja, sehingga guru lebih aktif dalam memberikan materi sedangkan siswa pasif mendengarkan. Di sekolah tersebut tersedia laboratorium komputer yang dapat digunakan sebagai sarana pembelajaran, sehingga penyampaian materi kepada siswa lebih mudah dan diharapkan daya serap mereka akan cepat. Tersedianya laboratorium komputer di SMA Negeri 17 Makassar merupakan alasan utama peneliti untuk melakukan penelitian di tempat tersebut. Selain itu, peneliti ingin memberikan gambaran yang luas kepada guru-guru yang ada di sekolah tersebut, bahwa pembelajaran dengan menggunakan kartu indeks dan soal-soal terstruktur berbasis ICT akan meningkatkan hasil belajar siswa, sebab dalam pelaksanaannya, siswa lebih mudah memahami konsep yang dipelajari melalui pemberian tes dan kartu indeks

\section{METODE PENELITIAN}

Penelitian ini adalah eksperimen semu yang bertujuan untuk mengetahui pengaruh penggunaan kartu indeks dan soal terstruktur berbasis ICT terhadap hasil belajar siswa. Penelitian ini mengkaji dua variabel, yaitu penggunaan kartu indeks dan soal terstruktur berbasis ICT sebagai variabel bebas dan hasil belajar sebagai variabel terikat. Desain penelitian yang digunakan Randomized Control-Group Only Design (Depdikbud, 1993), yaitu penelitian yang menggunakan dua kelompok yaitu kelompok eksperimen dan kelompok control.

Populasi penelitian adalah seluruh siswa kelas XI SMA Negeri 17 Makassaryang terdiri dari 6 kelas paralel dengan jumlah siswa secara keseluruhan adalah 180 orang siswa. Besarnya sampel ditetapkan sebanyak 60 responden (masing-masing 30 orang untuk kelompok kontrol dan kelompok eksperimen). Adapun cara penentuan sampel yaitu secara acak kelas, sehingga terpilih kelompok eksperimen dan kelompok kontrol. Data penelitian dianalisis dengan menggunakan statistik deskriptif dan stratistik inferensial dengan menghitung mean masing-masing kelompok yaitu $\mathrm{T}_{1}$ dan mencari perbedaan antara mean keduanya.

\section{HASIL DAN PEMBAHASAN}

Hasil belajar siswa yang diajar tanpa menggunakan kartu indeks dan soal-soal terstruktur berbasis ICT dapat dilihat pada Tabel 1 berikut:

Tabel 1. Statistik skor hasil belajar

\begin{tabular}{|l|c|}
\hline Statistik & Nilai \\
\hline Subyek & 28 \\
\hline Nilai tertinggi & 63 \\
\hline Nilair terendah & 20 \\
\hline Nilai ideal & 100 \\
\hline
\end{tabular}




\begin{tabular}{|l|c|}
\hline Rata-rata & 49,68 \\
\hline Modus & 57 \\
\hline Standar deviasi & 10,19 \\
\hline Varians & 103,88 \\
\hline
\end{tabular}

Data hasil penelitian memperlihatkan bahwa nilai tertinggi yang diperoleh siswa sebelum mengikuti pembelajaran dengan menggunakan kartu indeks dan soal-soal terstruktur berbaisis ICT adalah 63; nilai terendah 20; dan nilai rata-rata 49,68. Untuk lebih jelasnya dapat dilihat pada Gambar 1 berikut:

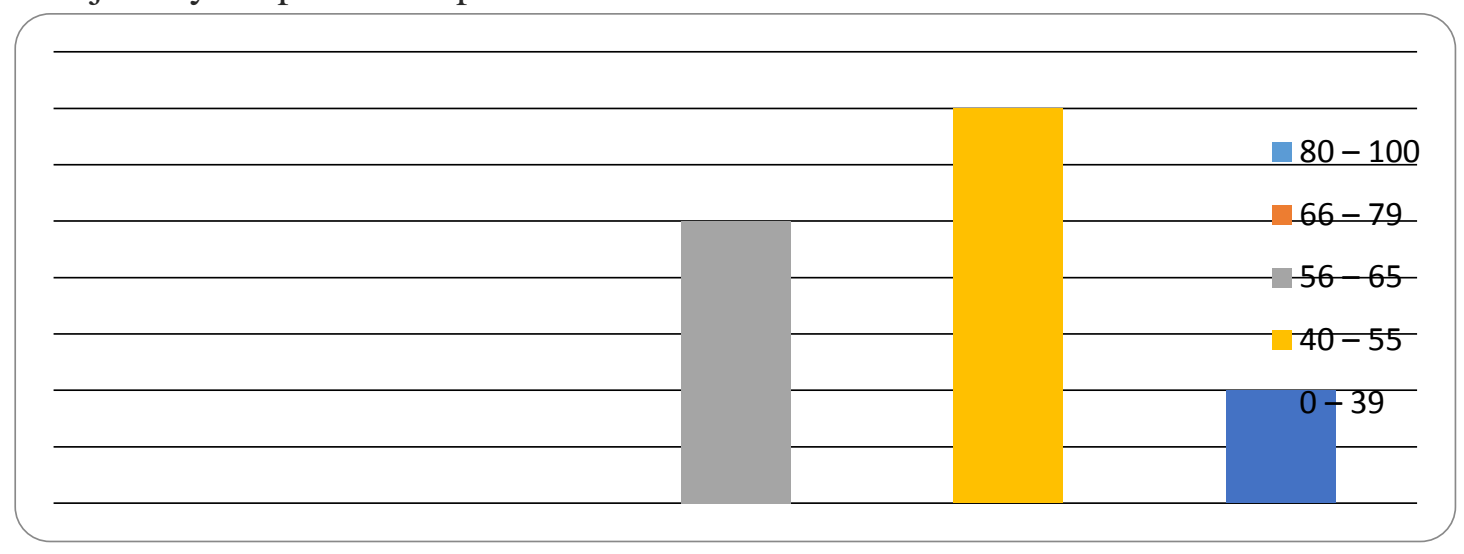

Gambar 1. Grafik batang hasil belajar siswa yang tanpa menggunakan kartu indeks dan soal-soal terstruktur berbasis $I C T$.

Hasil belajar siswa yang diajar dengan menggunakan kartu indeks dan soal-soal terstruktur berbasis ICT dapat dilihat pada Tabel 2 berikut:

Tabel 2. Statistik skor hasil belajar

\begin{tabular}{|l|c|}
\hline Statistik & Nilai \\
\hline Subyek & 28 \\
\hline Nilai tertinggi & 90 \\
\hline Nilair terendah & 73 \\
\hline Nilai ideal & 100 \\
\hline Rata-rata & 82,43 \\
\hline Modus & 80 \\
\hline Standar deviasi & 5,06 \\
\hline Varians & 25,60 \\
\hline
\end{tabular}

Data hasil penelitian memperlihatkan bahwa nilai tertinggi yang diperoleh siswa setelah mengikuti pembelajaran dengan menggunakan kartu indeks dan soal-soal terstruktur berbasisi ICT adalah 90; nilai terendah 73; dan nilai rata-rata 82,43. Untuk lebih jelasnya dapat dilihat pada gambar 2 berikut: 


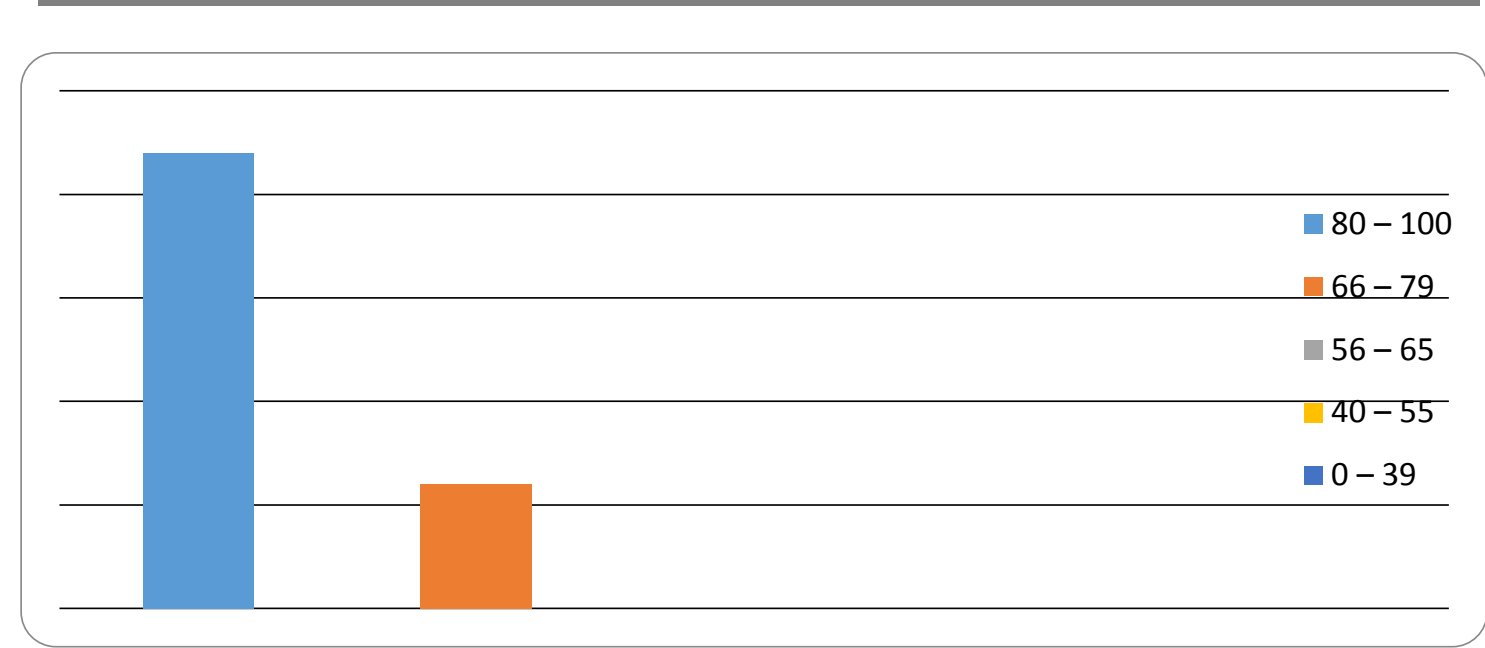

Gambar 2. Grafik batang hasil belajar siswa yang diajar dengan menggunakan kartu indeks dan soal-soal terstruktur berbasis $I C T$.

Nilai keseluruhan yang diperoleh siswa, jika dikelompokkan ke dalam lima kategori menurut (Arikunto, 2002) menurut sebaran distribusi frekuensi dan persentase serta kategori hasil belajar Biologi siswa kelas XI yang belajar dengan menggunakan kartu indeks dan soal-soal terstruktur berbasis ICT dan tanpa kartu indeks dan soal-soal terstruktur berbasis ICT dapat dilihat pada Tabel 3 berikut.

Tabel 3. Distribusi frekuensi, persentase dan kategori hasil belajar Biologi siswa kelas XI SMA Negeri 17

Makassar dengan dan tanpa kartu ndeks dan soal-soal terstruktur berbasis ICT.

\begin{tabular}{|c|c|c|c|c|l|}
\hline \multirow{2}{*}{ Interval Nilai } & \multicolumn{2}{|c|}{ Hasil Pretest } & \multicolumn{2}{|c|}{ Hasil Posttest } & \multirow{2}{*}{ Kategori } \\
\cline { 2 - 5 } & $\mathbf{F}$ & $\mathbf{P}(\mathbf{\%})$ & $\mathbf{F}$ & $\mathbf{P}(\boldsymbol{\%})$ & \\
\hline $80-100$ & 0 & 0 & 22 & 78,57 & S. Tinggi \\
\hline $66-79$ & 0 & 0 & 6 & 21,43 & Tinggi \\
\hline $56-65$ & 10 & 35,71 & 0 & 0 & Sedang \\
\hline $40-55$ & 14 & 50 & 0 & 0 & Rendah \\
\hline $0-39$ & 4 & 14,29 & 0 & 0 & S. Rendah \\
\hline Jumlah & $\mathbf{2 8}$ & $\mathbf{1 0 0}$ & $\mathbf{2 8}$ & $\mathbf{1 0 0}$ & \\
\hline
\end{tabular}

Tabel 3. tersebut menunjukkan bahwa dari 35 siswa kelas XI SMA Negeri 17 Makassar yang mengikuti pembelajaran Biologi tanpa menggunakan kartu indeks dan soal-soal terstruktur berbasis ICT adalah $0 \%$ siswa yang memperoleh nilai yang berada pada kategorikan sangat tinggi; 0\% dikategorikan tinggi; 35,71\% dikategorikan sedang; $50 \%$ dikategorikan rendah dan 14,29\% dikategorikan sangat rendah. Sedangkan dari 28 siswa kelas XI SMA Negeri 17 Makassar yang mengikuti pembelajaran Biologi dengan menggunakan kartu indeks dan soal-soal terstruktur berbasis ICT adalah 78,57\% siswa memperoleh nilai yang berada pada kategori sangat tinggi; 21,43\% dikategorikan tinggi; $0 \%$ dikategorikan sedang; $0 \%$ dikategorikan rendah; dan $0 \%$ dikategorikan sangat rendah. Hasil penelitian ini, menunjukkan bahwa siswa setelah belajar dengan menggunakan kartu indeks dan soal-soal terstruktur berbasis ICT memiliki hasil belajar yang lebih baik 
bila dibandingkan dengan sebelum belajar dengan menggunakan kartu indeks dan soalsoal terstruktur berbasis ICT. Siswa yang belajar setelah menggunakan kartu indeks dan soal-soal terstruktur berbasis ICT memiliki nilai rata-rata 82,43 dan tidak ada ditemukan siswa yang memiliki nilai pada kategori rendah atau sangat rendah, di mana nilai yang dominan diperoleh siswa berada pada kategori sangat tinggi yaitu 78,57\%. Untuk lebih jelasnya dapat dilihat pada gambar 3 berikut:

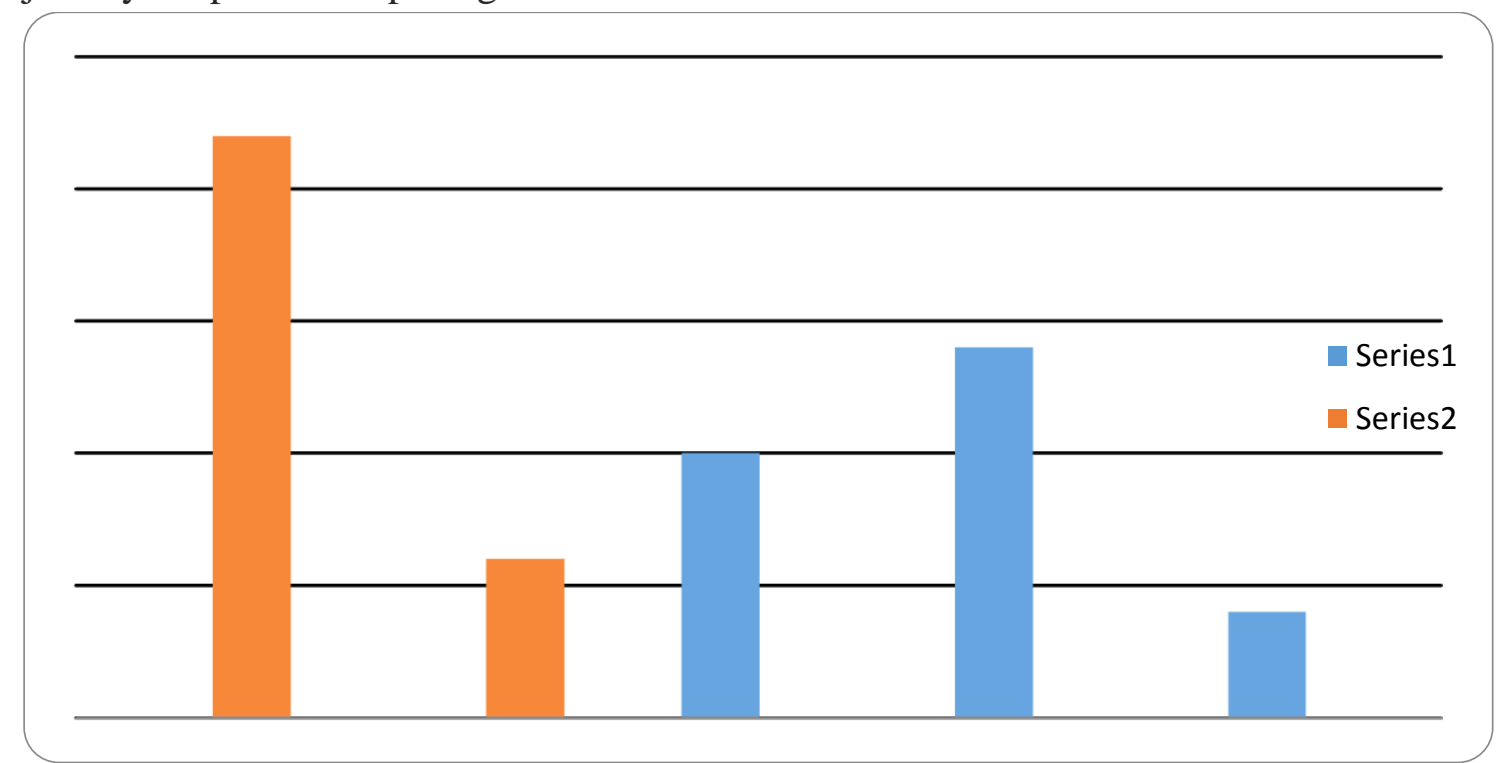

Gambar 3. Perbandingan hasil belajar siswa yang diajar dengan dan tanpa menggunakan kartu indeks dan soal-soal terstruktur berbasis $I C T$.

Berbeda halnya dengan siswa yang diajar tanpa menggunakan kartu indeks dan soal-soal terstruktur berbasis ICT memiliki nilai rata-rata kelas 49,68 dan masih ditemukan siswa yang memperoleh nilai pada kategori rendah dan sangat rendah. Hasil analisis data secara inferensial pada taraf kepercayaan $\mathrm{t}_{0,05}$ dan $\mathrm{t}_{0,01}$, didapat hasil bahwa $\mathrm{t}_{\text {hitung }}$ lebih besar dibandingkan dengan $\mathrm{t}_{\text {tabel. }}$. Nilai $\mathrm{t}_{\text {hitung }} 15,23$ sedangkan $\mathrm{t}_{\text {tabel }(0,05)}=1,67$ dan $t_{\text {tabel }(0,01)}=2,38$. Jadi ada pengaruh penggunaan kartu indeks dan soal-soal terstruktur berbasis ICT terhadap hasil belajar siswa kelas XI di SMA Negeri 17 Makassar.

Hasil analisis data yang telah diuraikan di atas, maka secara deskriptif hasil penelitian ini mengungkapkan bahwa hasil belajar Biologi siswa kelas XI SMA Negeri 17 Makassar setelah mengikuti pembelajaran dengan menggunakan kartu indeks dan soal-soal terstruktur berbasis ICT berada pada kategori sangat tinggi dengan nilai ratarata kelas 82,43 dan yang diajar tanpa menggunakan kartu indeks dan soal-soal terstruktur berbasis ICT berada pada kategori rendah dengan nilai rata-rata 49,68. Secara umum dapat dikatakan bahwa belajar dengan menggunakan media lebih baik bila dibandingkan tanpa menggunakan media. Menurut Raharjo (1991), media merupakan sarana yang sangat bermanfaat bagi siswa, dalam hal ini media memiliki banyak manfaat yaitu: 
mampu meningkatkan motivasi belajar siswa, memberikan variasi dalam belajar, memudahkan siswa dalam memahami materi pelajaran, siswa dapat belajar secara sistematis, mampu memberikan contoh yang autentik bagi siswa, dan mampu merangsang siswa untuk berpikir secara analisis.

Menurut Sidin dan Mohammad (2007) terdapat perbedaan yang signifikan atas pencapaian siswa yang diajar dengan menggunakan ICT. Hasil belajar siswa yang diajar dengan menggunakan ICT adalah lebih baik dari sudut bentuk, susun atur, pilihan warna serta semua pautannya berfungsi. Pennelitian ini menyatakan agar perubahan dibuat dalam sistem pedagogik agar konsisten dengan teori pembelajaran konstruktivisme dan diterapkan semasa belajar sekoah. Penelitian yang menyeluruh dan terus-menerus juga perlu dibuat terhadap pendekatan konstruktivisme agar kesan pembudayaan ICT di kalangan generasi muda berlaku secara berkesan dan berpanjangan. Jackson (2005) menyatakan informasi sekarang bermain bagian penting dalam kehidupan individu, organisasi dan lembaga dan informasi pada adalah kunci untuk menggunakan informasi yang optimal.

Selain pendapat tersebut, Sudjana (2005) mengungkapkan bahwa media memiliki manfaat bagi siswa dalam proses belajar mengajar di sekolah yaitu: dapat menarik perhatian siswa sehingga menumbuhkan motivasi dan minat belajar peserta didik, bahan yang akan diajarkan akan lebih jelas maknanya sehingga daya serap siswa jauh lebih besar bila dibandingkan belajar tanpa menggunakan media, siswa tidak akan bosan dalam belajar karena mereka akan berhadapan langsung dengan contoh dari setiap konsep yang dipelajari, dan menghilangkan sifat pasif siswa karena media dapat merangsang pola pikir anak dalam menafsirkan makna yang tercantum pada media yang digunakan. Menurut Idowu (2003), bahwa ICT telah memberikan sumbangan pada meningkatnya pertumbuhan penyediaan layanan. ICT memperlihatkan bahwa konektivitas ke internet dan yang sangat merusak kualitas layanan.

Siswa yang diajar tanpa menggunakan kartu indeks dan soal-soal terstruktur berbasis ICT cenderung memiliki nilai rata-rata kelas yang lebih rendah bila dibandingkan dengan siswa yang belajar dengan menggunakan kartu indeks dan soal-soal terstruktur berbasis ICT. Hal ini disebabkan oleh kurangnya motivasi dan minat belajar anak jika hanya menggunakan metode ceramah saja, tanpa ada contoh konkrit dari konsep yang dipelajari. Siswa yang belajar dengan hanya menggunakan satu panca indera akan menperoleh hasil yang lebih sedikit bila dibandingkan jika siswa belajar dengan mengandalkan atau menggunakan semua panca indera yang dimiliki. Belajar dengan menggunakan media berbasis kompuer akan memanfaatkan semua panca indera yang dimiliki, yaitu mulai dari penglihatan, pendegaran, dan merangsang aktivitas siswa dalam berkomunikasi. 


\section{KESIMPULAN}

Kesimpulan dari penelitian ini: (1) Siswa yang belajar dengan menggunakan kartu indeks dan soal-soal terstruktur berbasis ICT memiliki hasil belajar pada kategori tinggi dengan nilai rata-rata kelas adalah 82,43, (2) Siswa yang belajar tanpa menggunakan kartu indeks dan soal-soal terstuktur berbasis ICT memiliki hasil belajar pada kategori tinggi dengan nilai rata-rata kelas adalah 49,68, dan (3) Ada pengaruh penggunaan kartu indeks dan soal-soal terstruktur berbasis ICT terhadap hasil belajar siswa kelas XI di SMA Negeri 17 Makassar dengan nilai thitung lebih besar dengan tabel pada taraf kepercayaan $\alpha=0,05$ dan $\alpha=0,01$.

\section{SARAN}

Saran pada penelitian ini: (1) Bagi para guru, diharapkan mengajar dengan menggunakan multimedia (kartu indeks dan soal-soal terstruktur berbasis ICT) sehingga hasil belajar siswa dapat ditingkatkan, (2) Diharapkan kepada pihak sekolah untuk memberikan pelatihan kepada guru mengenai cara pembuatan dan mengoperasikan multimedia (multi media) sehingga target guru dalam mengajar bisa tercapai secara maksimal, (3) Kepada pihak sekolah, diharapkan untuk menyiapkan perangkat komputer di sekolah sebagai media pembelajaran yang cukup potensial dalam meningkatkan hasil belajar siswa, dan (4) Diharapkan kepada para peneliti selanjutnya untuk mengkaji lebih dalam lagi tentang pengaruh penggunaan kartu indeks dan soal-soal ter terhadap hasil belajar, aktivitas belajar, dan kinerja guru mengajar.

\section{DAFTAR PUSTAKA}

Depdikbud. 1993. Metode Penelitian Akta V. Depdikbud. Jakarta.

Djamarah, S. B, dan Zain, Aswan. 2002. Strategi Belajar Mengajar. Rineka Cipta. Jakarta.

Hamalik, Oemar. 1994. Multimedia Pendidikan. PT.Citra Aditya Bakti. Bandung.

Idowu B, Ogunbodede E, dan Idowu B. 2003. Information and Communication Technology in Nigeria The Helath Sector Experience. Journal of Informatin Technology Impact. Vol 3, No. 2 (69-76).

Jackson, M. 2005. The Impact of ICT on the Development of Information Literacy. Journal of eLiteracy. Vol 2 (15-26).

Poerwadarminta, W.J.S. 1996. Kamus Umum Bahasa Indonesia. Balai pustaka Jakarta

Sadiman, A.m 2001. Interaksi Dan Motivasi Belajar Mengajar. Raja Grafindo Persada. Jakarta.

Sidin, R. Dan Mohammad S.N. 2007. ICT Dalam Pendidikan: Prospek dan Gambaran dalam Pembaharuan. Jurnal Pendidikan (139-152).

Slameto 1995. Belajar Dan Faktor-Faktor Yang Mempengaruhinya Reneka cipta Jakarta. 
Sudjana, Nama, dan Rivai, Ahmatd 1997. Multi media Pembelajaran. Sinar Baru. Bandung. 